\title{
DHPLC technology for high-throughput detection of mutations in a durum wheat TILLING population
}

\author{
Pasqualina Colasuonno*, Ornella Incerti, Maria Luisa Lozito, Rosanna Simeone, Agata Gadaleta and Antonio Blanco
}

\begin{abstract}
Background: Durum wheat (Triticum turgidum L.) is a cereal crop widely grown in the Mediterranean regions; the amber grain is mainly used for the production of pasta, couscous and typical breads. Single nucleotide polymorphism (SNP) detection technologies and high-throughput mutation induction represent a new challenge in wheat breeding to identify allelic variation in large populations. The TILLING strategy makes use of traditional chemical mutagenesis followed by screening for single base mismatches to identify novel mutant loci. Although TILLING has been combined to several sensitive pre-screening methods for SNP analysis, most rely on expensive equipment. Recently, a new low cost and time saving DHPLC protocol has been used in molecular human diagnostic to detect unknown mutations.

Results: In this work, we developed a new durum wheat TILLING population (cv. Marco Aurelio) using 0.70-0.85 \% ethyl methane sulfonate (EMS). To investigate the efficiency of the mutagenic treatments, a pilot screening was carried out on 1,140 mutant lines focusing on two target genes (Lycopene epsilon-cyclase, $\varepsilon-L C Y$, and Lycopene beta-cyclase, $\beta-L C Y$ involved in carotenoid metabolism in wheat grains. We simplify the heteroduplex detection by two low cost methods: the enzymatic cleavage (Cell)/agarose gel technique and the denaturing high-performance liquid chromatography (DHPLC). The Cell/agarose gel approach allowed us to identify 31 mutations, whereas the DHPLC procedure detected a total of 46 mutations for both genes. All detected mutations were confirmed by direct sequencing. The estimated overall mutation frequency for the pilot assay by the DHPLC methodology resulted to be of 1/77 kb, representing a high probability to detect interesting mutations in the target genes.

Conclusion: We demonstrated the applicability and efficiency of a new strategy for the detection of induced variability. We produced and characterized a new durum wheat TILLING population useful for a better understanding of key gene functions. The availability of this tool together with TILLING technique will expand the polymorphisms in candidate genes of agronomically important traits in wheat.
\end{abstract}

Keywords: Durum wheat, TILLING, SNP markers, DHPLC

\section{Background}

Traditional chemical induced mutations together with the modern SNP detection technologies are an attractive mixture of procedures to explore gene function and for the production of phenotypic variants in traits of agronomic interest, especially in species with complex genomes such as grasses [1].

The Targeting Induced Local Lesions IN Genomes (TILLING) technique is a mutational approach widely

\footnotetext{
*Correspondence: pattybiotec@yahoo.it

Department of Soil, Plant and Food Sciences, section of Genetic and Plant Breeding, University of Bari "Aldo Moro", Via G. Amendola 165/A, 70126 Bari, Italy
}

(c) 2016 Colasuonno et al. Open Access This article is distributed under the terms of the Creative Commons Attribution 4.0 International License (http://creativecommons.org/licenses/by/4.0/), which permits unrestricted use, distribution, and reproduction in any medium, provided you give appropriate credit to the original author(s) and the source, provide a link to the Creative Commons license, and indicate if changes were made. The Creative Commons Public Domain Dedication waiver (http://creativecommons.org/publicdomain/zero/1.0/) applies to the data made available in this article, unless otherwise stated.

exploited to screen for single base changes induced by chemical mutagenesis (usually ethyl methane sulfonate, EMS) in target genes [2-4]. The main effort is to analyze large mutant populations through DNA samples organized in pools, followed by mutant pool detection and validation of the individual carrying the mutation by sequencing. The recent technological advances have led to improve the performance in cost and time allowing to combine traditional mutation programs to high-throughput pre-screening techniques [5-9].

TILLING can be carried out using different procedures, such as the heteroduplex mismatch cleavage assay through single-strand-specific endonuclease CelI [10], 
the DNA melting temperature analysis [11] and the deep sequencing of pooled DNA [12]. The CelI assay represents the most popular, accessible and low-cost method to detect mutations in large populations [13]. It has been combined with agarose gel detection approaches [14-16], with a non-denaturing polyacrylamide method $[9,17]$ or a gel based system (LI-COR DNA analyzer) requiring labeled PCR primers $[10,18]$.

The mutation scanning High Resolution DNA Melting (HRM) method takes advantage of the denaturing dynamics of double-stranded DNA after PCR amplification and heteroduplex formation. The single base changed in mutant lines is detected by observing a slight shift in the melting temperature compared to the wild-type homoduplexes. Other pre-screening methods for SNP detection based on DNA melting temperature, such as Denaturing Gradient Gel Electrophoresis (DGGE) [19], Single-Strand Conformational Polymorphism (SSCP) [20] and Mass Spectrometry (MS) [21], were found to have limitations in terms of sensitivity, costs and suitability for high-throughput screening.

Although the sequencing is the direct method to reveal mutations, its application is beyond the budget of low-to-medium-throughput academic laboratories. In the last few years, the progresses of Next-Generation Sequencing (NGS) technologies have helped to bypass some limits of the conventional TILLING approaches such as SNP detection in pools with more than eight individuals [22]. The NGS progresses have converted the TILLING strategy into an in silico procedure denominated TILLING by Sequencing (TbyS) [12]. This approach has been performed considering the complete coding region of each mutant genome (exome) organized in a multidimensional pool system [23]. Despite the several advantages of TbyS combined with Exome Capture strategy, its applicability continues to be restricted for the money input required per single capture reaction and the genome complexity of crop species.

A recently developed and powerful technique, commonly referred to as Denaturing High Performance Liquid Chromatography (DHPLC), allows the detection of single base substitutions as well as small insertions and/or deletions in a large number of samples [24]. In brief, this method detects mismatches through heteroduplex formation between wild-type and mutated DNA strands. Heteroduplex molecules are obtained by mixing, denaturing and re-annealing the PCR products; the samples are then separated by reverse-phase liquid chromatography on a special column matrix with partial heat denaturation of DNA strands [25]. So far, DHPLC is mainly used in human diagnosis to detect mutations involved in several diseases $[26,27]$ and to assess antibiotic resistance mutations in microbial communities [28]. In plants, DHPLC has been applied in the analysis of natural variations [29], varietal traceability [30] and candidate gene studies [31]. As a pre-screening method in TILLING strategy, DHPLC has been first adopted in Arabidopsis thaliana [32] through melting temperature analysis and in barley [33] in combination with $\mathrm{CelI}$ endonuclease.

Durum wheat [Triticum turgidum (L.) subsp. durum (Desf.) Husn.] represents one of the most challenging candidates for the TILLING technology because of its genome characteristics, such as the presence of genes in two homoeologous copies (in A and B genomes) sharing 93-96\% sequence identity, the large genome size $(\sim 13,000 \mathrm{Mb})$, the high portion of repetitive DNA (83\%) and the low gene density [34]. In this vein, the TILLING strategy is important for reverse genetic studies and for the genetic improvement of wheat. It is applied in wheat as functional and/or alternatively to non-genetically manipulation (GM) technique.

Here we report the development of a durum wheat TILLING population and its characterization through TILLING strategy analyzing two target genes (Lycopene epsilon-cyclase, $\varepsilon-L C Y$, and Lycopene beta-cyclase, $\beta$ - $L C Y$ ), key enzymes involved in carotenoid biosynthetic pathway [35]. High levels of carotenoid pigments in durum wheat are favored by breeders and consumers for wheat flour/ end-product color and for human diet because of their nutritional properties. $\varepsilon$-LCY and $\beta$-LCY are respectively responsible for lutein and $\beta$-carotene (a provitamin A precursor) accumulation during endosperm development [35-37]. In contrast to $\varepsilon-L C Y$ genes ( $\mathrm{A}$ and $\mathrm{B}$ genomes) that have been cloned and characterized [38], $\beta-L C Y$ genes are not well understood in the molecular structural genes. For the first time we optimized in durum wheat the TILLING procedure for an efficient SNP detection by DHPLC and we compared two low-cost screening methods: the most popular CelI cleavage assay based on agarose gel detection and the reviewed DHPLC technique. The simplicity of the DHPLC technique will be demonstrated and it will make possible new applications of SNPbased markers for crop breeding programs.

\section{Methods}

\section{Plant material}

Seeds of the Italian durum wheat cultivar Marco Aurelio (high grain yield, excellent yellow index and protein content and gluten strength) were used for the EMS mutagenesis treatment. A set of nulli-tetrasomic lines (NT) of Triticum aestivum cv. Chinese Spring lacking group 3 and 6 chromosomes $[39,40]$ were used to assess the genomespecific primers.

\section{EMS mutagenesis and production of the wheat TILLING population}

Marco Aurelio seeds were treated with EMS as reported by Uauy et al. (2009) [9]. To test the 'kill curve', batches 
of 100 seeds each were treated with different EMS concentrations $(0.00,0.60,0.70,0.80,0.90$ and $1.00 \%)$ at two exposure times (7 and $18 \mathrm{~h}$ ) in the growth chamber. Based on the germination rate, the $18 \mathrm{~h}$-treatment with the range of 0.70-0.85 \% EMS was chosen to mutagenize $\sim 32,000$ seeds. The EMS-treated seeds $\left(\mathrm{M}_{1}\right)$ were sown in the experimental field of University of Bari (Valenzano, Italy) in 2012. One spike from each $\mathrm{M}_{1}$ plant was collected and $10 \mathrm{M}_{2}$ seeds were sown in the field to obtain the $\mathrm{M}_{2}$ generation. At the tillering stage, leaves for DNA extraction were collected from one random plant from each $M_{2}$ progeny. $M_{3}$ seeds from each $M_{2}$ plant were harvested and stored at $4{ }^{\circ} \mathrm{C}$ under vacuum conditions.

\section{Genomic DNA extraction and pooling}

Genomic DNA was isolated from leaves of individual $\mathrm{M}_{2}$ plants, using the Dellaporta et al. (1983) DNA extraction protocol. Approximately $100 \mathrm{mg}$ of lyophilized leaves were placed in $2 \mathrm{~mL}$ single tubes containing 2 steel beads $(4 \mathrm{~mm})$ and tissues were crashed using the TissueLyser system (Qiagen) two times for $45 \mathrm{sec}$ at $30 \mathrm{~Hz}$. Genomic DNA was measured at spectrophotometer (Nano-Drop $^{\text {Tu }} 1000$, Thermo Scientific), diluted to a concentration of $90 \mathrm{ng} / \mathrm{ml}$ and checked on a $1 \%$ agarose gel using $\lambda$ DNA (Invitrogen) as a concentration reference. Then, $\mathrm{M}_{2}$ plant DNA was pooled four-fold in a 96-well format. 1,140 $\mathrm{M}_{2}$ plants from three $\mathrm{M}_{2}$ plant DNA subsets, derived from different EMS treatments $(0.70,0.75$ and $0.80 \%$ ) (380 mutant plants per each), were used for the molecular screening for a total of three 96-well plates.

\section{Candidate genes and PCR amplification}

The complete wheat coding sequences of the $\varepsilon-L C Y$ genes (A and B genomes) (GeneBank: EU649785, EU649786) were identified on NCBI (National Center for Biotechnology Information, [41]). For $\beta-L C Y$ gene, sequence information were partial available (GeneBank: AK334392, JN622196, FJ814767 and BT009216), and two of them were reported as $\beta-L C Y$ complete coding sequence (FJ814767 and JN622196). All these sequences were subjected to bioinformatic analysis via Aegilops tauschii genome sequence database [42] and CerealsDB site [43] to distinguish the A and B genome homoeologous copies, and via SoftBerry [44] to predict the gene structures. The final gene sequences were reported into the Additional file 1: Supplemental file S1.

Both target genes were analyzed by CODDLE software (Choose codons to Optimize the Detection of Deleterious Lesions, [45]) to identify the optimal target regions, and aligned in BLAST to highlight the differences between homoeologous sequences. All primer pairs were set using Primer3 [46] (Table 1). Based on observed genome differences, primer pairs were tested on DNA of Chinese Spring nulli-tetrasomic lines of chromosome groups 3 (N3A-T3B, N3B-T3D) and 6 (N6A-T6B, N6B-T6D).

Since we used two different pre-screening methods (CelI/agarose gel and DHPLC), the primer combinations changed based on the technical requirements of each strategy. For the $\varepsilon-L C Y-3 A$ and $\varepsilon-L C Y-3 B$ genes, the CODDLE predicted target gene regions (exons 4-8) were longer than 1,600 bp. Thus, in CelI/agarose system the amplicons covering exons 4-8 were obtained with the primer pairs PC35f-PC40r (1,193 bp) for $\varepsilon-L C Y-3 A$ and PC42f-PC46r (1,530 bp) for $\varepsilon-L C Y-3 B$ (Table 1$)$. In DHPLC analysis, PCR primers for $\varepsilon-L C Y$ genes were designed dividing the target gene region into three parts: PC35f-PC130r, PC42f-PC40r and PC43fPC37r amplicons for A genome and PC44f-PC140r, PC41f-PC143r and PC147f-PC48r amplicons for B genome.

On the other hand, the $\beta-L C Y$ gene regions analyzed through CelI/agarose gel system corresponded to two amplicons of $861 \mathrm{bp}$ in A genome (F4f-PC63r) and $990 \mathrm{bp}$ in B genome (PC71f-PC63r). For DHPLC analysis, amplicon region sizes were limited to the first part of $\beta-L C Y$ exon 1 and precisely on 464 for A genome (F4f-OP6r) and $761 \mathrm{bp} \mathrm{B}$ genome (PC68f-OP6r). Even for $\beta-L C Y$ genes, genome-specific primers were assessed combining one specific genome primer with another one amplifying both homoeologous genome copies.

PCR reactions were carried out in a $20 \mu \mathrm{l}$ volume, containing individual or pooled DNA, $\mathrm{dH}_{2} \mathrm{O}, 1 \mathrm{X}$ Phusion $\mathrm{HF}$ Buffer, $0.2 \mathrm{mM}$ each dNTP, $0.3 \mu \mathrm{M}$ each primer, $0.015 \mathrm{U}$ Phusion High-Fidelity DNA Polymerase (Finnzymes). PCR reaction was conducted using a Bio-Rad thermocycler as follow: $98{ }^{\circ} \mathrm{C}$ for $30 \mathrm{sec}$ for initial denaturation, followed by 30 cycles at $98{ }^{\circ} \mathrm{C}$ for $10 \mathrm{sec}$, an annealing temperature specific for each primer pair for $30 \mathrm{sec}, 72{ }^{\circ} \mathrm{C}$ for $40 \mathrm{sec}$, one cycle at $72{ }^{\circ} \mathrm{C}$ for $10 \mathrm{~min}$ and $4{ }^{\circ} \mathrm{C}$ hold for storage. After PCR amplification, $3 \mu \mathrm{l}$ of each amplified product were checked on $1 \%$ agarose gel to verify the primer efficiency and the DNA concentration before the next TILLING step.

\section{Cell nuclease digestion and mutation detection on agarose gel}

Once the amplification and denaturing steps were done, $12-15 \mu \mathrm{l}$ of PCR products ( 600 ng) were digested with Surveyor CelI enzyme (Transgenomic, Omaha, NE, USA). For each CelI digestion, $1.2 \mu \mathrm{l}$ of $\mathrm{MgCl}_{2}(0.15 \mathrm{mM}), 1.2 \mu \mathrm{l}$ of Enhancer Cofactor, $0.2 \mu \mathrm{l}$ of Surveyor enhancer W and $0.2 \mu \mathrm{l}$ of Surveyor nuclease were gently vortexed, added to PCR amplification and incubated at $42{ }^{\circ} \mathrm{C}$ for $60 \mathrm{~min}$. Then nuclease digestion was ended with $2 \mu$ l of STOP solution and $3 \mu \mathrm{l}$ of bromophenol blue loading dye for visualization on 1-2\% agarose gel. 
Table 1 Primer pairs used to amplify the $\varepsilon-L C Y$ and $\beta$-LCY genes. The final two columns give the size of amplicons and the used high-throughput technology (Cell/agarose gel or DHPLC method). The partial denaturation DHPLC temperatures are reported in brackets

\begin{tabular}{|c|c|c|c|c|c|c|}
\hline Gene & Genome & Exon region & Primer & Sequence $\left(5^{\prime}-3^{\prime}\right)$ & Amplicon size (bp) & Method \\
\hline \multirow[t]{4}{*}{$\beta-L C Y-6 A$} & A & 1 & F4f & AGCCCTACAACCCGGGA & 861 & Cell/agarose gel \\
\hline & & & PC63r & CCCATGAAGATCTTGAGA & & \\
\hline & & & F4f & AGCCCTACAACCCGGGA & 464 & $\mathrm{DHPLC}\left(65.8^{\circ} \mathrm{C}\right)$ \\
\hline & & & OP6r & GTGCGCGCCACCATGTACC & & \\
\hline \multirow[t]{4}{*}{$\beta-L C Y-6 B$} & B & 1 & PC71f & ATCCCGGCCACCGTCGTCCTGGA & 990 & Cell/agarose gel \\
\hline & & & PC62r & CCATGAAGATCTTGAGATGC & & \\
\hline & & & PC68f & GTCTTCATCGACGACCACA & 761 & $\mathrm{DHPLC}\left(65.1^{\circ} \mathrm{C}\right)$ \\
\hline & & & OP6 & GTGCGCGCCACCATGTACC & & \\
\hline \multirow[t]{10}{*}{$\varepsilon-L C y-3 A$} & A & $4-9$ & PC35f & TGCTGAGAAGGTAGACATTCTATTG & 1,193 & Cell/agarose gel \\
\hline & & & PC40r & CAAGCATTGATGGACTGGAC & & \\
\hline & & $4-5$ & $P C 35 f^{a}$ & TGCTGAGAAGGTAGACATTCTATTG & 650 & DHPLC $\left(57.8^{\circ} \mathrm{C}\right)$ \\
\hline & & & PC130r ${ }^{a}$ & CATTGCAGAAGCACACTGC & & \\
\hline & & $6-7-8$ & $P C 42 f^{a}$ & GGTTGATGTCTCGGTTGGAT & 443 & $\operatorname{DHPLC}\left(57.9^{\circ} \mathrm{C}\right)$ \\
\hline & & & PC40r ${ }^{a}$ & CAAGCATTGATGGACTGGAC & & \\
\hline & & $8-9$ & PC43f & TGGACAATATTTGCCTGGAA & 385 & $\mathrm{DHPLC}\left(57.5^{\circ} \mathrm{C}\right)$ \\
\hline & & & PC37r & CTTGCGTACTCGCGAAAAA & & \\
\hline & & & PC35f & TGCTGAGAAGGTAGACATTCTATTG & 1,527 & Used for nested PCR \\
\hline & & & PC37r & CTTGCGTACTCGCGAAAAA & & \\
\hline \multirow[t]{8}{*}{$\varepsilon-L C y-3 B$} & $\mathrm{~B}$ & $4-9$ & PC42f & GGTTGATGTCTCGGTTGGAT & 1,530 & Cell/agarose gel \\
\hline & & & PC46r & GCATCCTTGCGTATTGTATTCTT & & \\
\hline & & 4 & $P C 44 f^{a}$ & TTGCTGAGAAGGTACATTCGAT & 336 & $\operatorname{DHPLC}\left(58.4^{\circ} \mathrm{C}\right)$ \\
\hline & & & PC140r ${ }^{a}$ & GGCACTTTGTGCAGGGTTGG & & \\
\hline & & $5-6-7$ & PC41f & GAGGACCACGTGTTTGTTG & 584 & $\operatorname{DHPLC}\left(58.1^{\circ} \mathrm{C}\right)$ \\
\hline & & & PC143r & ACACCTGTGCAAGATAAACC & & \\
\hline & & $7-8-9$ & PC147f & TCCTTACCTAACACAGACCAGA & 636 & $\operatorname{DHPLC}\left(58.2^{\circ} \mathrm{C}\right)$ \\
\hline & & & PC48r & AAAGATACGCATCCTTGCGTATT & & \\
\hline
\end{tabular}

${ }^{\text {a }}$ Primer combinations required nested PCR

The protocol for SNP detection method through CelI/ agarose gel has been applied according to Uauy et al. (2009) [9] with one modification: after each PCR reaction and agarose gel check, denaturing and re-annealing steps for heterduplexes formation were performed at $95{ }^{\circ} \mathrm{C}$ for $3 \mathrm{~min}$.

\section{DHPLC mutation detection}

The DHPLC analysis was performed using Transgenomic WAVE system (Transgenomic) equipped with a DNASep HT cartridge, solvent degasser unit, binary pump, autosampler (model 7250), oven (L-7310 T), accelerator and variable wavelength detector (UV/Vis/ fluorescent). DNA fragments were separated using two buffers: buffer A (aqueous solution of 0.1 M TEAA, $\mathrm{pH}$ 7.0) and buffer B (aqueous solution of 0.1 M TEAA, pH 7 with $25 \%$ (v/v) acetonitrile).
DHPLC system was tested before each plate runs by injecting the three molecular standards (Transgenomic): WAVE DNA Sizing Control (analyzed at $50{ }^{\circ} \mathrm{C}$ ), WAVE High-Range Mutation Marker $\left(70{ }^{\circ} \mathrm{C}\right)$ and WAVE LowRange Mutation Marker $\left(56{ }^{\circ} \mathrm{C}\right)$ according to the supplier's recommendations. After each injection run, cleaning of the column was performed with buffer D (solution containing $75 \%$ acetonitrile and $25 \%$ water).

The preliminary CelI digestion test in the Transgenomic WAVE system was carried out using two case-control wheat DNAs. Single homoduplex PCR products (PC133fPC130r primers) were mixed in equal molarity in two-fold PCR pools and cleaved using $2 \mu \mathrm{l}$ of CelI. Each digestion was injected onto the WAVE system and either loaded on agarose gel to confirm the cleavage patterns. Amplicons were ran on DHPLC in Universal Linear gradient at $50{ }^{\circ} \mathrm{C}$. The detected samples traces were compared in UV 
(260 nm) and in WAVE High Sensitivity System using the intercalating fluorescent WAVE Optimized HS Staining Solution. Putative mutations were identified by the presence of two chromatogram peaks whose size added up to the full length PCR product.

Molecular screening of the TILLING population was performed under the mutation detection Rapid DNA program. Amplicons were injected on the DHPLC and undergone partial denaturation method. Optimal temperature for SNP scanning was determined using DHPLC Navigator ${ }^{\mathrm{m}}$ Software (Transgenomic) (Table 1). The column mobile phase consisted of different ratios of buffer A (ranging from $49-40 \%$ ) and buffer B (ranging from 51-60 \%) in a mixture with varying acetonitrile concentrations based on the amplicon sequence and size.

Fourfold pools showing mutant profiles were opened and mixed in mutant DNA two-fold pools, heated and loaded again to identify the single plant carrying the mutation. DNAs of detected mutant lines were then sequenced by Sanger method.

\section{Results and Discussion}

Optimal mutagenesis conditions and development of the TILLING population

An optimal mutagen dosage is important to obtain individuals carrying a high mutation load with vigorous growth and fertility [13, 47, 48]. Therefore, to determine the concentration of mutagen treatment specific for the durum wheat cv. Marco Aurelio and to balance maximum mutation load with an acceptable plant survival rate, we carried out incubations for sets of 100 seeds with EMS concentrations ranging from 0.0 to $1.0 \%$ at two different exposure times (7 and $18 \mathrm{~h}$ ). As a large number of sulfur compounds, EMS exhibits high volatility and instability considering atmosphere oxidation and temperature [49]. According to our previous observation on the different EMS activities between batches, the following conditions were used: fresh EMS solution for each treatment step, controlled environmental temperature $\left(25^{\circ} \mathrm{C}\right)$ and a rotary shaker at a constant speed (112.5 rpm). After incubation and repeated washes, $\mathrm{M}_{1}$ treated seeds were sown, and germination rate was determined after six days (Table 2). As expected, the

Table 2 Germination rate (\%) of Marco Aurelio seeds treated with different EMS concentrations and two exposure times (7 and 18 h). Results refer to 100 seed batches for each treatment in root-trainers in the growth chamber

\begin{tabular}{lllllll}
\hline Exposure time (h) & \multicolumn{6}{l}{ EMS concentration (\%) } \\
\cline { 2 - 7 } & 0.00 & 0.60 & 0.70 & 0.80 & 0.90 & 1.00 \\
\hline $7 \mathrm{~h}$ & 100 & 70 & 59 & 40 & 28 & 10 \\
$18 \mathrm{~h}$ & 92 & 69 & 61 & 28 & 30 & 10 \\
\hline
\end{tabular}

germination rates gradually decreased from $70 \%$ to $10 \%$ by increasing the EMS concentration from 0.60 to $1.00 \%$, respectively (both at $7 \mathrm{~h}$ and $18 \mathrm{~h}$ of incubation). A significantly different germination rate of $40 \%$ and $28 \%$ at $0.80 \%$ EMS was observed at the two different time exposure.

Seeds treated with 0.7 and $0.8 \%$ EMS for $7 \mathrm{~h}$ showed values of 59 and $40 \%$ of germination rate, respectively, in comparison with the untreated control $(100 \%)$, while a very low germination rate $(10 \%)$ was observed for the $1.00 \%$ EMS treatment. After $18 \mathrm{~h}$ of incubation, the germination rate varied slightly between seed lots at 0.70-0.60 \% EMS treatments and severely decreased for the $0.80-1.00 \%$ EMS dosage (28 and $10 \%$, respectively). At $0.70 \%$ EMS treatment for 7 and $18 \mathrm{~h}$, similar value of germinability was observed. The comparison between the two experiments showed a slight decrement of seed vitality from 7 to $18 \mathrm{~h}$ treatment, as confirmed by the germination rates of the untreated seeds. Based on these results, we decided to use a range of EMS dosage (0.70-0.85 \%) at $18 \mathrm{~h}$ treatment for a large-scale mutagenesis to obtain high mutation density and a survival rate of approximately $40 \%$.

Seeds were mutagenized with $0.70,0.75,0.80$ and $0.85 \%$ EMS for $18 \mathrm{~h}$ incubation and grown in field conditions. Out of 32,000 treated seeds, 6,745 $\mathrm{M}_{1}$ plants (21\%) produced filled spikes, while the rest died or produced sterile spikes (Table 3 ). The mortality rate was $77-80 \%$ at $0.70-0.80 \%$ EMS concentration, while a higher value of $88.7 \%$ of mortality was observed with the $0.85 \%$ EMS treatment. In total, at $\mathrm{M}_{3}$ generation we obtained 6,460 plants (0.70-0.85 \% EMS population), including 2,000 lines treated at $0.70 \%$ EMS dosage, 3,400 lines at $0.75 \%$ EMS, 984 lines at $0.80 \%$ EMS and 361 lines at $0.85 \%$ EMS.

\section{Candidate genes}

Once the mutagenized durum population was available, a pilot assay was performed to determine the mutation frequency and the suitability of each TILLING population subsets. For this analysis, DNAs from a total of 1,140 plants (380 plants from the $0.70,0.75$ and $0.80 \%$ EMS dosages) were pooled in groups of four DNAs and

Table 3 Mortality rate (\%) in $M_{1}$ plants for each selected EMS concentration (\%)

\begin{tabular}{llllc}
\hline EMS (\%) & $\begin{array}{l}\text { Seed } \\
\text { quantity (gr) }\end{array}$ & $\begin{array}{l}\mathrm{N}^{\circ} \text { of } \\
\text { seeds }\end{array}$ & $\begin{array}{l}\mathrm{N}^{\circ} \text { of } \mathrm{M}_{1} \\
\text { plants }\end{array}$ & $\begin{array}{l}\text { Mortality } \\
\text { rate (\%) }\end{array}$ \\
\hline 0.70 & 720 & 9,600 & 2,000 & 79.2 \\
0.75 & 1,080 & 14,400 & 3,400 & 76.4 \\
0.80 & 360 & 4,800 & 984 & 79.5 \\
0.85 & 280 & 3,200 & 361 & 88.7 \\
Total & 2,440 & 32,000 & 6,745 & 78.9 \\
\hline
\end{tabular}


Table 4 Characterization of the $\beta-L C Y$ and $\varepsilon-L C Y$ genes: gene size (bp), number of exons and introns, the predicted regions by CODDLe program in terms of exon region and region length (bp) and the considered amplicon size for the TILLING strategy

\begin{tabular}{|c|c|c|c|c|c|c|}
\hline \multirow[t]{2}{*}{ Gene } & \multirow[t]{2}{*}{ Size (bp) } & \multirow[t]{2}{*}{ Number of exons } & \multirow[t]{2}{*}{ Number of introns } & \multicolumn{2}{|c|}{ CODDLe prediction } & \multirow{2}{*}{$\begin{array}{l}\text { TILLING approach } \\
\text { Amplicon size (bp) }\end{array}$} \\
\hline & & & & Exon region & Length (bp) & \\
\hline$\beta-L C Y-6 A$ & 1,703 & 1 & 0 & 1 & 400 & 880 \\
\hline$\beta-L C Y-6 B$ & 1,455 & 1 & 0 & 1 & 400 & 875 \\
\hline$\varepsilon-L C Y-3 A$ & 4,652 & 10 & 9 & $4-8$ & 1,299 & 1,163 \\
\hline$\varepsilon-L C Y-3 B$ & 4,435 & 10 & 9 & $4-8$ & 1,299 & 789 \\
\hline
\end{tabular}

organized into three 96-well plates for convenient screening.

The genotypes were screened for the detection of mutations in two carotenoid genes: Lycopene epsiloncyclase $(\varepsilon-L C Y)$ and Lycopene beta-cyclase $(\beta-L C Y)$. A region of $\sim 1,300$ bp for the $\varepsilon-L C Y-3 A$ and $\varepsilon-L C Y-3 B$ genes and one of $\sim 800-900$ bp for the $\beta-L C Y-6 A$ and $\beta-L C Y-6 B$ genes were selected for the pilot assay on the sub-set of $\mathrm{M}_{2}$ lines (Table 4). Amplicon size varied on the bases of the SNP detection method: in the CelI assay based on agarose gel, we considered PCR products up 1,000 bp, while in the DHPLC method, we set the amplicon length with a maximum of $800 \mathrm{bp}$.

\section{Optimization of TILLING procedure through DHPLC}

In order to test the performance of the DHPLC scanning procedure for SNPs in mixed PCR amplicons, a known polymorphism A- $>$ G at 2,709 bp position of exon 5 of $\varepsilon-L C Y-3 A$ was chosen for analysis in the case-control durum wheat genotypes cvs. Saadi and Casanova.

The DHPLC procedure involved the evaluation of two pre-screening methods of SNP detection: DHPLC combined to CelI endonuclease digestion and DHPLC using melting temperature analysis. The DHPLC/CelI optimization was carried out exploring data from UV and Fluorescence analysis. The $\varepsilon-L C Y-3 A$ amplicon groups corresponding to PC133f-PC130r from cvs. Saadi and

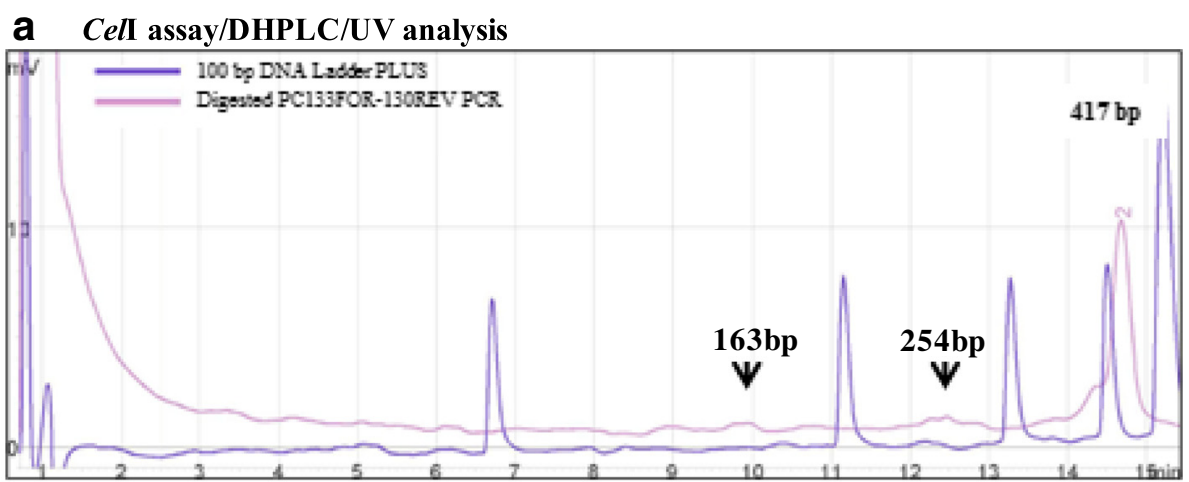

b CeII assay/DHPLC/Fluorescence analysis $417 \mathrm{bp}$

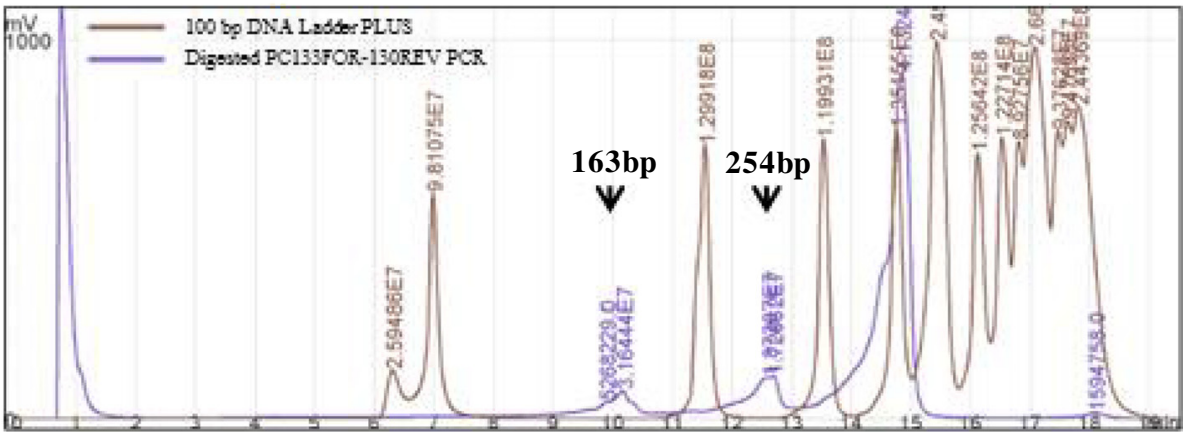

Fig. 1 Comparisons of Cell/DHPLC analysis using UV detector (a) and fluorescent detector (b). Chromatograms show the DHPLC run of PC133f-PC130r amplicons from mixed DNA. All runs are compared to 100 bp DNA Ladder PLUS. The black arrows indicate the putative expected heteroduplex molecules. The number above the main peak marked the region amplified length 
Casanova DNAs in equal molarity and in homoduplex status were mixed in two-fold PCR DNA, heated, cooled down to achieve heteroduplex formation and digested with $0.2 \mu \mathrm{l} \mathrm{CelI} \mathrm{enzyme.} \mathrm{The} \mathrm{DHPLC/CelI} \mathrm{size} \mathrm{criteria}$ (universal linear gradient type application) were satisfied by the amplicons, which was ranging from 100 to $1,000 \mathrm{bp}$ and a minimum distance of $50 \mathrm{bp}$ between primers and SNP location.

The amplicon length in the DHPLC/CelI chromatograms was in agreement with the PCR product size in both analysis, as confirmed by the presence of a single peak corresponding to the full-length fragment compared to the $100 \mathrm{bp}$ DNA ladder PLUS. Regarding the heteroduplex cleavage profile (Fig. 1), the heteroduplex PC133f-PC130r amplicon showed the expected pattern of three peaks (two heteroduplex molecules corresponding to $163 \mathrm{bp}$ and $254 \mathrm{bp}$ peaks, and one homoduplex molecule of $417 \mathrm{bp}$ ) only in the fluorescence analyses. Even if the heteroduplex peaks were revealed and confirmed, the presence of SNP appeared as low traces (height peaks of $\sim 40 \mathrm{mV}$ compared to the homoduplex peak $\sim 1,000 \mathrm{mV}$ ). The SNP detection signal could be covered by the PCR background noise (Fig. 1).

Generally, the issues to be taken into consideration for CelI/DHPLC include the addition of CelI reaction, the availability of a fluorescent detector (as here demonstrated to have major sensitivity in cleaved fragment resolution), the number of variable sites within the target region and the amplicon length $(100-1,000 \mathrm{bp}$ in size). The CelI/DHPLC approach increases the economic costs and time of its application, since it requires a running time of $20 \mathrm{~min} / \mathrm{sample}$. The possibility of producing labmade CelI endonuclease [50] could reduce costs but the sensitivity of the fluorescent detector still remains a limit, as confirmed by the noise level of the chromatograms due to interfered factors with the enzyme cleavage and their accumulation in the chromatographic column.

Alternatively to the DHPLC/CelI method, we considered a fast run time of 3 min through DHPLC based on the reduction of melting temperature between homo- and heteroduplex molecules. The criteria of DHPLC in melting temperature analysis consisted in high PCR product yields $(\sim 500 \mathrm{ng})$ and fragment size $\geq 200$ and $\leq 800 \mathrm{bp}$. According to this, we focused on the melting profile of the PC133f-PC130r PCR product using the Navigator ${ }^{\text {ra }}$ software (Transgenomic). It establishes whether any significant shifts in $\mathrm{T}_{\mathrm{m}}$ could be predicted for the amplicon. The predicted melting temperatures $\left(57.7^{\circ} \mathrm{C}\right)$ was tested to determine the optimal run and heteroduplex visualization after denaturating/reannealing steps (Fig. 2).

The DHPLC-melting temperature analysis displayed to be more analytically sensitive and adaptable to a hightroughput format. The cost can be further reduced

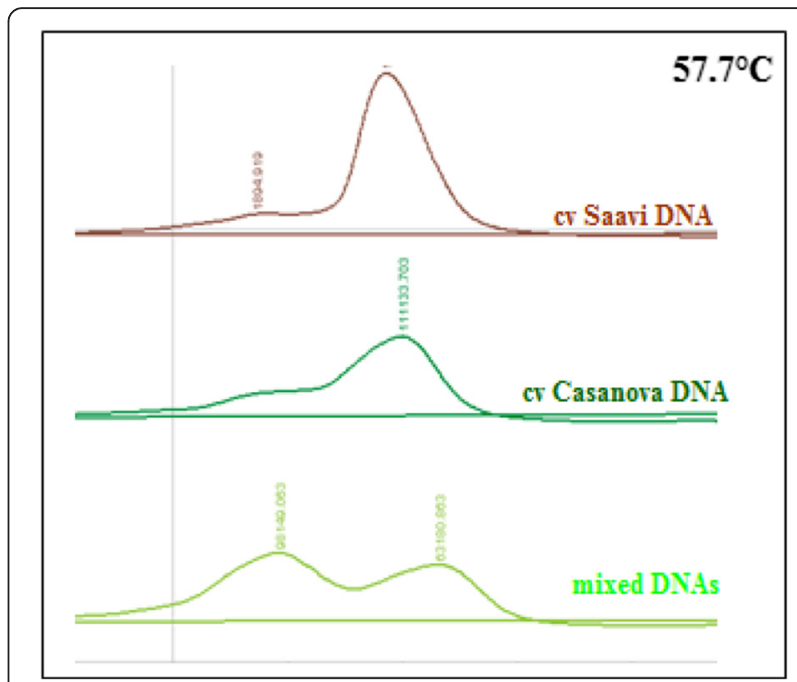

Fig. 2 Outline of SNP detection by heteroduplex analysis of PC133fPC130r amplicons of $\varepsilon-L C Y-3 A$ gene. The chromatograms correspond to elution profile of homoduplex samples (cv. Saavi DNA in brown line and cv. Casanova DNA in dark green line) and the double peak of heteroduplex mixed DNA (green line). All runs were conducted at the same melting temperature in DNA Rapid program $\left(57.7^{\circ} \mathrm{C}\right)$

combining amplicons with different size but the same melting temperature profile in one run (under detection mutation parameters). Other considerations that should be considered to succeed with the DHPLC method are the fragment length (200-800 bp of size) and the presence of multiple thermal profiles that could require more than one temperature-gradient condition. All the candidate genes in the present work $(\beta-L C Y$ and $\varepsilon-L C Y)$ were optimized for heteroduplex detection in only one melting temperature.

The DHPLC protocol optimization also involved the adjustment of sample DNA concentration in terms of

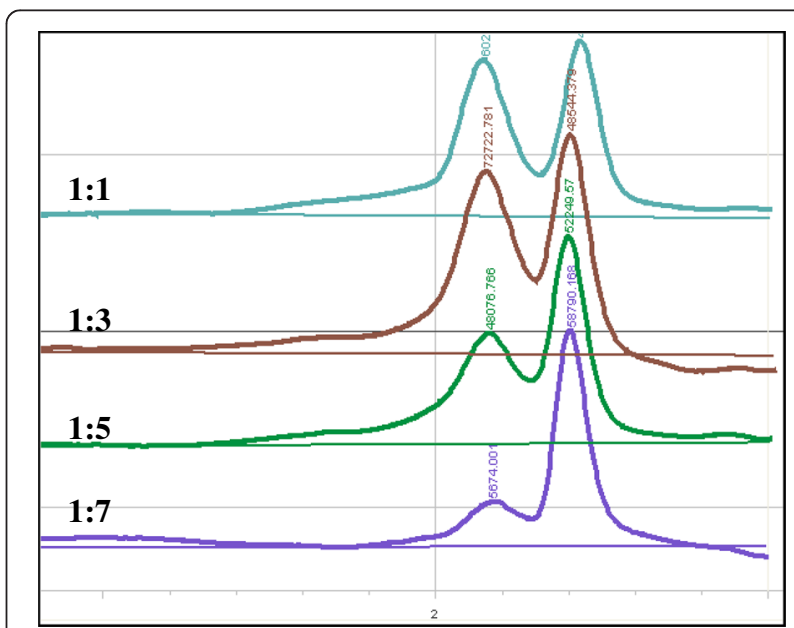

Fig. 3 The pool depth setting for SNP detection. From the top line to the bottom, PC133f-PC130r PCR products from cvs. Saadi and Casanova are mixed together in proportions of 2, 4, 6 and 8 fold pools 
Table 5 Mutation frequencies obtained through DHPLC analysis on 1,140 screened plants of the mutagenized durum wheat cv. Marco Aurelio

\begin{tabular}{|c|c|c|c|c|c|c|c|}
\hline Gene & Primer & & Exon region & Amplicon size (bp) & Mutation $\mathrm{n}^{\circ}$ & Mutati & $y(1 / \mathrm{kb})$ \\
\hline$\beta-L C Y-6 A$ & F4f-OP6r & & 1 & 464 & 17 & & $1 / 31$ \\
\hline$\beta-L C Y-6 B$ & PC68f-OP6r & & 1 & 761 & 8 & & $1 / 108$ \\
\hline \multirow[t]{4}{*}{$\varepsilon-L C Y-3 A$} & PC35f-PC130r & & $4-5$ & 650 & 12 & $1 / 62$ & \\
\hline & PC42f-PC40r & & $6-7-8$ & 443 & 2 & $1 / 252$ & \\
\hline & PC43f-PC37r & & $8-9$ & 384 & 3 & $1 / 146$ & \\
\hline & & mean & & & & & $1 / 102$ \\
\hline \multirow[t]{4}{*}{$\varepsilon-L C Y-3 B$} & PC44f-PC140r & & 4 & 336 & 4 & $1 / 95$ & \\
\hline & PC41f-PC143r & & $5-6-7$ & 584 & 7 & $1 / 95$ & \\
\hline & PC147f-PC48r & & $7-8-9$ & 636 & 10 & $1 / 72$ & \\
\hline & & mean & & & & & $1 / 84$ \\
\hline Total/mean & & & & 4,258 & 46 & & $1 / 77$ \\
\hline
\end{tabular}

pool size. Exactly $12 \mu \mathrm{l}$ of PCR products from cvs. Saadi and Casanova were mixed together in proportions of 1:1, 1:3, 1:5 and 1:7 (Fig. 3). As expected, a progressive reduction in SNP detection was observed with the increment of the pool level: the heteroduplex molecules were still visible up to the pool ratio of 1:5. The 1:3 pooling size was chosen for the $\mathrm{M}_{2}$ DNA arrangement.

\section{Induced mutation screening using the DHPLC and comparison with Cell-agarose}

The screening of the TILLING durum population included a pilot assay of DNAs arranged in four fold pools. According to Uauy et al. (2009) [9], the applied TILLING strategy was based on the initial screening of four-fold DNA pools to identify the mutant DNA and a second screening of two-fold DNA pools to identify the mutant individual for sequencing. The analysis was performed on the DHPLC technique using the melting temperatures defined in the optimization assay. Screening the $\varepsilon-L C Y$ and $\beta-L C Y$ genes, we identified a total of 46 mutations. The mutation density was calculated by dividing the total number of base pairs screened (this means the amplicon length multiplied by the total number of mutant lines) by the number of the detected mutations. The mutation density was estimated to be of $1 / 77 \mathrm{~kb}$. Translating into single genes, we revealed 25 mutations for $\beta-L C Y$ genes $(1,225 \mathrm{bp}$ analyzed in total) and 38 mutations for $\varepsilon$ - LCY $(2,747$ bp screened for $\mathrm{A}$ and $\mathrm{B}$ genomes) genes (Table 5 ).

We tried to simplify the SNP detection in TILLING population comparing results of two low cost procedures: DHPLC in melting parameters and CelI-cleaved products on conventional agarose gel. Although the CelI/agarose procedure is clearly a simplification of the TILLING technique, the efficiency of parameters were not so immediately obvious. We tested all the important parameters such as CelI concentration, size of scanning windows and overall robustness of the method.

Using CelI-agarose methods, we estimated a mutation frequency of $1 / 168 \mathrm{~kb}$ (31 mutations) for both genes. In particular, we yielded 11 and 20 mutations for $\beta-L C Y$ (1,861 bp screened in total) and $\varepsilon-L C Y(2,723 \mathrm{bp})$ genes, respectively (Table 6).

Overall, the highest number of identified mutations was observed in the conserved region of 464 bp size of $\beta-L C Y-6 A$ gene (17 mutations) and in the $\sim 600$ bp regions of $\varepsilon-L C Y$ - $3 A$ amplicon $1 \mathrm{~A}$ and $\varepsilon-L C Y-3 B$ amplicon 3B (12 and 10 mutations, respectively). Each method identified 26 heterozygous loci detected by the other one. All mutations were confirmed by direct sequencing. The mutant genotypes were in heterozygous state, excepting for 12 homozygous mutations in in $\varepsilon-L C Y-3 A$

Table 6 Mutation frequencies obtained through Cell/agarose method on 1,140 screened plants of the mutagenized durum wheat cv. Marco Aurelio

\begin{tabular}{|c|c|c|c|c|c|}
\hline Gene & Primer & Exon region & Amplicon size (bp) & Mutation $n^{\circ}$ & Mutation frequency $(1 / \mathrm{kb})^{\mathrm{a}}$ \\
\hline$\beta-L C Y-6 A$ & F4f-PC63r & 1 & 871 & 5 & $1 / 176$ \\
\hline$\beta-L C Y-6 B$ & PC71f-PC62r & 1 & 990 & 6 & $1 / 167$ \\
\hline$\varepsilon-L C Y-3 A$ & PC35f-PC40r & $4-8$ & 1,193 & 9 & $1 / 138$ \\
\hline$\varepsilon-L C Y-3 B$ & PC44f-PC46r & $4-8$ & 1,530 & 11 & $1 / 148$ \\
\hline Total/mean & & & 4,584 & 31 & $1 / 168$ \\
\hline
\end{tabular}

${ }^{\mathrm{a}}$ The fragment size of each gene was reduced to $100 \mathrm{bp}$ because of PCR artefacts 
and $\varepsilon-L C Y-3 B$ genes. As expected because of the EMS alkylation, all of induced mutations were $\mathrm{G}$ to $\mathrm{A}$ or $\mathrm{C}$ to $\mathrm{T}$ transitions.

The 31 mutations (corresponding to 1/168 kb) detected on agarose gel could give a wrong consideration of the mutation density rate of the durum TILLING population. Unlike that of the DHPLC genotyper, the sensitivity of SNP detection on agarose gels is low although it can be sufficient to test only the presence/absence of SNPs in small DNA populations.

\section{Conclusions}

The results obtained by the use of DHPLC in melting temperature conditions demonstrated this method is an excellent alternative approach for mutation screening in wheat TILLING populations. Although DHPLC requires an initial investment in terms of instrument, consumable and eventually CelI endonuclease kit, it proved to be outsourced from a direct sequencing service, less expensive and more sensitive than cleavage assay based on agarose gel. Finally, this is the first report of TILLING study in durum wheat, providing good evidence of DHPLC applicability and potentiality in SNP detection in target genes. The availability of these tool, together to the continue increase number of SNP markers by genotyping array services, could expand the use of SNP markers in durum wheat breeding programs.

\section{Additional file}

Additional file 1: Supplemental file S1. $\beta-L C Y$ gene sequences. (DOCX $12 \mathrm{~kb}$ )

\section{Abbreviations \\ CODDLE: choose codons to optimize the detection of deleterious lesions: DGGE: denaturing gradient gel electrophoresis; DHPLC: denaturing high performance liquid chromatography; EMS: ethyl methane sulphonate; EST: expressed sequence tags; HRM: High Resolution DNA Meltin; MS: Mass Spectrometry; NGS: next-generation sequencing; PCR: polymerase chain reaction; SSCP: single-strand conformational polymorphism; SNP: single nucleotide polymorphism; TILLING: targeted induced local lesions in genomes; TbyS: TILLING by sequencing; $\varepsilon$-LCY: lycopene epsilon-cyclase; $\beta$-LCY: lycopene beta-cyclase.}

\section{Competing interests}

The author declare that they have no competing interests.

\section{Authors' contributions}

PC and OI developed the mutant population. PC, OI and MLL were responsible for DNA extraction, sample normalization and seed stock organization. PC and $O$ isolated genome specific primers for $\varepsilon-L C Y$ and $\beta-L C Y$ genes, respectively. PC performed the DHPLC method for TILLING strategy. OI and MLL performed the Cell/agarose screening. AG, RS and AB conceived the study, obtained funding for it and were primarily responsible for drafting and revising the manuscript with contributions from co-authors. All authors read and approved the final manuscript

\section{Acknowledgements}

This work was supported by the financial support of Italian MIUR Projects "PON-ISCOCEM" and "PRIN 2010-11".
Received: 28 April 2015 Accepted: 8 February 2016

Published online: 17 February 2016

\section{References}

1. Ahloowalia BS, Maluszynski M, Nichterlein K. Global impact of mutationderived varieties. Euphytica. 2004;135:187-204.

2. Till BJ, Reynolds SH, Weil C, Springer N, Burtner C, Young K, et al. Discovery of induced point mutations in maize genes by TILLING. BMC plant biology. 2004;4:12

3. Till BJ, Zerr T, Comai L, Henikoff S. A protocol for TILLING and Ecotilling in plants and animals. Nat Protoc. 2006:1(5):2465-77.

4. Comai L, Young K, Till BJ, Reynolds SH, Greene EA, Codomo CA, et al. Efficient discovery of DNA polymorphisms in natural populations by Ecotilling. Plant J. 2004;37:778-86.

5. Bovina R, Brunazzi A, Gasparini G, Sestili F, Palombieri S, Botticella E, et al. Development of a TILLING resource in durum wheat for reverse- and forward-genetics analyses. Crop and Pasture Science. 2014;65:112-24.

6. Salvi S, Druka A, Milner SG, Gruszka D. Induced Genetic Variation, TILLING and NGS-Based Cloning. Biotec Approac Barley Improv. Springer Berl Heidelberg. 2014;15:287-310.

7. Slade AJ, Fuerstenberg SI, Loeffler D, Steine MN, Facciotti D. A reverse genetic, nontransgenic approach to wheat crop improvement by TILLING. Nat Biotechnol. 2005;23(1):75-81

8. Slade AJ, McGuire C, Loeffler D, Mullenberg J, Skinner W, Fazio G, et al. Development of high amylose wheat through TILLING. BMC Plant Biol. 2012;12:69.

9. Uauy C, Paraiso F, Colasuonno P, Tran RK, Tsai H, Berardi S, et al. A modified TILLING approach to detect induced mutations in tetraploid and hexaploid wheat. BMC plant biology. 2009;9:115.

10. Colbert T, Till BJ, Tompa R, Reynolds S, Steine MN, Yeung AT, et al. High-throughput screening for induced point mutations. Plant Phys. $2001 ; 126: 480-4$

11. Zhou L, Vandersteen J, Wang L, Fuller T, Taylor M, Palais B, et al. High-resolution DNA melting curve analysis to establish HLA genotypic identity. Tissue Antigens. 2004;64:156-64.

12. Tsai H, Howell T, Nitcher R, Missirian V, Watson B, Ngo KJ, et al. Discovery of rare mutations in populations: TILLING by sequencing. Plant Physiol. 2011;156(3):1257-68.

13. Till BJ, Colbert T, Tompa R, Enns LC, Codomo CA, Johnson JE, et al. High-throughput TILLING for functional genomics. Methods Mol Biol. 2003;236:205-20.

14. Sato $Y$, Shirasawa $K$, Takahashi $Y$, Nishimura M, Nishio T. Mutant selection from progeny of gamma-ray-irradiated rice by DNA heteroduplex cleavage using Brassica petiole extract. Breeding Sci. 2006:56:179-83.

15. Rawat N, Sehgal SK, Joshi A, Rothe N, Wilson DL, McGraw N, et al. A diploid wheat TILLING resource for wheat functional genomics. BMC Plant Biol. 2012;12:205.

16. Wu JL, Wu C, Lei C, Baraoidan M, Bordeos A, Madamba MR, et al. Chemical- and irradiation-induced mutants of Indica Rice IR64 for forward and reverse genetics. Plant Mol Biol. 2005:59:85-97.

17. Raghavan C, Naredo M, Wang H, Atienza G, Liu B, Qiu F, et al. Rapid method for detecting SNPs on agarose gels and its application in candidate gene mapping. Mol Breed. 2007;19:87-101.

18. Minoia S, Petrozza A, D'Onofrio O, Piron F, Mosca G, Sozio G, et al. A new mutant genetic resource for tomato crop improvement by TILLING technology. BMC Res Notes. 2010;3:69.

19. Li J, Berbeco R, Distel RJ, Jänne PA, Wang L, Makrigiorgos GM. s-RT-MELT for rapid mutation scanning using enzymatic selection and real time DNAmelting: new potential for multiplex genetic analysis. Nucleic Acids Res. 2001;35:e84.

20. Hestekin CN, Barron AE. The potential of electrophoretic mobility shift assays for clinical mutation detection. Electrophoresis. 2006;27:3805-15.

21. Buetow KH, Edmonson M, MacDonald R, Clifford R, Yip P, Kelley J, et al. High-throughput development and characterization of a genomewide collection of gene-based single nucleotide polymorphism markers by chip-based matrix-assisted laser desorption/ionization time-of-flight mass spectrometry. Proc Natl Acad Sci U S A. 2001;98:581-4.

22. Wang TL, Uauy C, Robson F, Till B. TULLING in extremis. Plant Biotechnol J. 2012;10(7):761-72

23. Henry IM, Nagalakshmi U, Lieberman MC, Ngo KJ, Krasileva KV, Vasquez-Gross $\mathrm{H}$, et al. Efficient genome-wide detection and cataloging 
of EMS-induced mutations using exome capture and next-generation sequencing. The Plant cell. 2014;26(4):1382-97.

24. Xiao W, Oefner PJ. Denaturing high-performance liquid chromatography: A review. Hum Mutat. 2001:17:439-74.

25. Keller G, Hartmann A, Mueller J, Hofler H. Denaturing high pressure liquid chromatography (DHPLC) for the analysis of somatic p53 mutations. Lab Invest. 2001;81(12):1735-7.

26. Wagner T, Stoppa-Lyonnet D, Fleischmann E, Muhr D, Pagès S, Sandberg T, et al. Denaturing high-performance liquid chromatography detects reliably BRCA1 and BRCA2 mutations. Genomics. 1999;62:369-76.

27. Pilato B, De Summa S, Danza K, Papadimitriou S, Zaccagna P, Paradiso A, et al. DHPLC/SURVEYOR nuclease a sensitive, rapid and affordable method to analyze BRCA1 and BRCA2 mutations in breast cancer families. Mol Biotechnol. 2012;52(1):8-15

28. Randall LP, Coldham NG, Woodward MJ. Detection of mutations in Salmonella enterica gyrA, gyrB, parC and parE genes by denaturing high performance liquid chromatography (DHPLC) using standard HPLC instrumentation. J Antimicrob Chemoth. 2005;56:619-23.

29. Spiegelman Jl, Mindrinos MN, Fankhauser C, Richards D, Lutes J, Chory J, et al. Cloning of the RSF1 gene in Arabidopsis thaliana using a mapping strategy based on high density DNA arrays and denaturing high performance liquid chromatography. Plant Cell. 2000;12:2485-98.

30. Giancaspro A, Colasuonno P, Zito D, Blanco A, Pasqualone A, Gadaleta A. Varietal traceability of bread "Pane Nero di Castelvetrano" by denaturing high pressure liquid chromatography analysis of single nucleotide polymorphisms. Food Control. 2016;59(1):809-17.

31. Lexer C, Welch ME, Durphy JL, Rieseberg LH. Natural selection for salt tolerance quantitative trait loci (QTLs) in wild sunflower hybrids: implications for the origin of Helianthus paradoxus, a diploid hybrid species. Mol Ecol. 2003:12:1225-35.

32. McCallum CM, Comai L, Greene EA, Henikoff S. Targeting induced local lesions in genomes (TILLING) for plant functional genomics. Plant Physiol. 2000;123(2):439-42.

33. Caldwell DG, McCallum N, Shaw P, Muehlbauer GJ, Marshall DF, Waugh R. A structured mutant population for forward and reverse genetics in Barley (Hordeum vulgare L.). Plant J. 2004;40(1):143-50.

34. Trick M, Adamski N, Mugford S, Jiang CC, Febrer M, Uauy C. Combining SNP discovery from next-generation sequencing data with bulked segregant analysis (BSA) to fine-map genes in polyploid wheat. BMC Plant Biol. 2012;12:14.

35. Nisar N, Li L, Lu S, Khin NC, Pogson BJ. Carotenoid metabolism in plants. Mol Plant. 2015;8:68-82.

36. Blanco A, Colasuonno P, Gadaleta A, Mangini G, Schiavulli A, Simeone R, et al. Quantitative trait loci for yellow pigment concentration and individual carotenoid compounds in durum wheat. J Cereal Science. 2011;54(2):255-64.

37. Colasuonno P, Gadaleta A, Giancaspro A, Nigro D, Giove S, Incerti O, et al. Development of a high-density SNP-based linkage map and detection of yellow pigment content QTLs in durum wheat. Mol Breed. 2014;34(4):1563-78.

38. Howitt CA, Cavanagh CR, Bowerman AF, Cazzonelli C, Rampling L, Mimica $J$, et al. Alternative splicing, activation of cryptic exons and amino acid substitutions in carotenoid biosynthetic genes are associated with lutein accumulation in wheat endosperm. Funct Integr Genomics. 2009;9:363-76.

39. Sear ER. The aneuploids of common wheat. Missouri Agric Exp Stn Res Bull. 1954:572:1-58

40. Sears ER. Nullisomic-tetrasomic combinations in hexaploid wheat. In: Riley R, Lewis KR, editors. Chromosome manipulations and plant genetics. Edinburgh: Oliver and Boyd Ltd; 1966. p. 29-45.

41. NCBI [http://www.ncbi.nlm.nih.gov/]

42. Aegilops tauschii BLAST Search [http://avena.pw.usda.gov/RHmapping/blast/ blast.html]

43. Cerealsdb [http://www.cerealsdb.uk.net/cerealgenomics/Index_Home.html]

44. Softberry [http://linux1.softberry.com/berry.phtml]

45. Proweb [http://blocks.fhcrc.org/proweb/]

46. Primer3 [http://bioinfo.ut.ee/primer3-0.4.0/]

47. Till BJ, Cooper J, Tai TH, Colowit P, Greene EA, Henikoff S, et al. Discovery of chemically induced mutations in rice by TILLING. BMC plant biology. 2007;7:19.
48. Henikoff S, Comai L. Single-nucleotide mutations for plant functional genomics. Annu Rev Plant Biol. 2003:54:375-401.

49. Wang T, Uauy C, Till B, Liu CM. TILLING and associated technologies. J Integr Plant Biol. 2010;52:1027-30.

50. Galeano CH, Gomez M, Rodriguez LM, Blair MW. CEL I nuclease digestion for SNP discovery and marker development in common bean (Phaseolus vulgaris L.). Crop Sci. 2009;49:381-94.

\section{Submit your next manuscript to BioMed Central and we will help you at every step:}

- We accept pre-submission inquiries

- Our selector tool helps you to find the most relevant journal

- We provide round the clock customer support

- Convenient online submission

- Thorough peer review

- Inclusion in PubMed and all major indexing services

- Maximum visibility for your research

Submit your manuscript at www.biomedcentral.com/submit
Biomed Central 